\title{
Vivências Acadêmicas em Estudantes Universitários do Estado do Rio de Janeiro
}

\author{
Adriana Benevides Soares ${ }^{a, b *}$, Monique de Oliveira Moura Baldez ${ }^{a}$, \\ \& Thatiana Valory dos Santos Mello ${ }^{\text {a, }}$ \\ ${ }^{\mathrm{a}}$ Universidade Salgado de Oliveira, Niterói, Brasil, ${ }^{\mathrm{b}}$ Universidade do Estado do Rio de Janeiro, Rio de Janeiro, Brasil \\ \& ${ }^{c}$ Universidade Estácio de Sá, Rio de Janeiro, Brasil
}

\begin{abstract}
RESUMO
Esta pesquisa buscou identificar e comparar as características da adaptação à universidade dos estudantes do ensino superior, nas seis mesorregiões do Estado do Rio de Janeiro. O instrumento, Questionário de Vivências Acadêmicas, foi aplicado em 500 estudantes. Encontrou-se, como principais resultados, que os estudantes da Região Metropolitana têm melhores escores no item "base para o curso", que os alunos da Região Sul Fluminense apresentam maiores escores para os itens "relação com a família", "autonomia pessoal", "métodos de estudo", "adaptação à instituição", "gestão de recursos", "autoconfiança", "percepção de competência pessoal" e "ansiedade na realização de exames" e que os estudantes da Região Norte Fluminense tiveram melhor desempenho nos itens "bem estar físico", "bem estar psicológico" e "relacionamento com os professores".
\end{abstract}

Palavras-chave: experiências acadêmicas; mesorregiões do Rio de Janeiro; ensino superior; integração acadêmica.

\begin{abstract}
Academic Experiences of Students from the State of Rio de Janeiro

This study aimed to identify and compare the defining features of adaptation to university of students of higher education in the six broad regions of the State of Rio de Janeiro. An instrument test, the Academic Experiences Questionnaire, was applied to 500 students. The main results obtained were that the students from the metropolitan region have better scores in "background for the course"; students from the southern region of the State had higher scores in the topics "family relationships", "self autonomy", "study methods", "adapting to the institution", "resource management", "selfassurance", "perception of self-competence" and "anxiety during exams"; and students from the region north of the State had better performance in the topics "physical welfare", "psychological welfare" and "relationship with teachers".
\end{abstract}

Keywords: academic experiences; broad-regions of Rio de Janeiro; higher education; academic integration.

$\mathrm{O}$ ingresso na universidade é um momento de satisfação para o aluno, que vê concretizada, pelo resultado de seu desempenho acadêmico, a realização de seu esforço e dedicação pessoal. Ao passar a euforia inicial, o aluno começa a se preocupar, gerar expectativas e dúvidas sobre o que esperar desta nova etapa a ser vivida. Como será a instituição que vai frequentar, as disciplinas que vai cursar, os amigos que vai encontrar, professores com que vai se relacionar e, enfim, quais serão as dificuldades a superar.

Pesquisas realizadas sobre vivências acadêmicas e adaptação à universidade sugerem que a maioria dos alunos que ingressam no curso superior revela percalços pessoais e acadêmicos de diferentes naturezas

Endereço para correspondência: Adriana Benevides Soares, Universidade Salgado de Oliveira, Rua Marechal Deodoro, 263, Centro, Niterói, RJ, CEP 24030-060. E-mail: adribenevides@gmail.com. 
(Almeida, Soares, \& Ferreira, 1999; Cunha \& Carrilho, 2005; Ferreira, Almeida, \& Soares, 2001; Pires, Almeida, \& Ferreira, 2000; Polydoro, Primi, Serpa, Zaroni, \& Pombal, 2001; Soares, Guisande, Almeida, \& Páramo, 2008; Soares, Poubel, \& Mello, 2009).

Conforme explicitado em Cunha e Carrilho (2005), Almeida (1998) sugere que um entendimento mais apropriado do ajustamento e do êxito acadêmico dos estudantes universitários pode ser identificado pelas experiências vivenciadas no processo de ingresso ao ensino superior. As características dessa passagem e a adequação do aluno a esta nova realidade baseam-se no seu desenvolvimento intelectual e social e da estrutura de apoio que a instituição possa prover (Azevedo \& Faria, 2001, 2006; Parker, Summerfeldt, Hogan, \& Majeski, 2004).

$\mathrm{O}$ ambiente acadêmico tem sido considerado como determinante para o desenvolvimento do estudante, pois lhe proporciona a possibilidade de compartilhar, com várias pessoas, ideias e experiências inovadoras (Almeida \& Soares, 2004; Granado, Santos, Almeida, Soares, \& Guisande, 2005; Pascarella \& Terenzini, 2005). Desta forma, o comportamento dos alunos tem uma atuação crucial, uma vez que essa transição ocorre em função da qualidade da interação entre eles e das ferramentas institucionais disponíveis assim como do seu nível acadêmico anterior (Soares, Almeida, Diniz, \& Guisande, 2006; Soares e cols., 2008).

Para muitos autores, é importante entender bem o processo de interação entre a instituição e os alunos e as transformações realizadas a partir desta interação (Almeida, 1998; Almeida e cols., 1999; Almeida \& Soares, 2004; Pires e cols., 2000; Vendramini e cols., 2004). A estrutura da universidade, as oportunidades que ela oferece, recursos materiais e ferramentas operacionais, normas, comunidade, prestação de serviços, currículo dos docentes, programas e eventos institucionais, são fatores que interferem na percepção do estudante, no seu comprometimento e em sua adaptação acadêmica. Para Pascarella e Terenzini (1991), Polydoro (2000) e Polydoro e cols. (2001), o contexto ambiental e relacional são fontes de mudanças cognitivas e afetivas e, portanto, propiciam vivências adaptativas ao estudante, que quer se integrar ao novo contexto que se apresenta: a universidade.

Este novo contexto universitário está impregnado de características próprias da Região em que está inserido. Ambientes de cultura mais acolhedora podem ser capazes de propiciar, mais rapidamente, o estabelecimento de novas amizades e melhor relação com os professores, assim como ambientes mais cosmopolitas podem não favorecer as ligações afetivas, mas, por serem mais competitivos, podem propiciar mais autonomia pessoal e, também, mais ansiedade no momento da realização de exames.

A busca pela empregabilidade pode também ser determinante no modo como o estudante se adapta à universidade. Em regiões com vocações econômicas específicas, a formação de determinados profissionais vinculados a áreas prioritárias gera a absorção dos recém-formados quase que imediatamente após a conclusão do curso. Em metrópoles onde a diversidade e a escassez de emprego são maiores, tem-se como consequência o acirramento da busca do melhor desempenho e do perfil ideal exigido pelo empregador. Essas características podem nortear o perfil do estudante universitário. Segundo Balassiano, Seabra e Lemos (2005), existe impacto significativo da escolaridade no acesso ao emprego e no salário do trabalhador e é possível constatar um aumento importante da remuneração para as faixas de maior escolaridade.

No estado do Rio de Janeiro, existem 148 campi, 2.165 instituições de ensino superior, 20.407 cursos, 305.960 funções docentes e 4.453.156 matrículas (INEP, 2006). Estes números representam uma população universitária bastante significativa, distribuída em regiões do Estado com características diferentes: Metropolitana, Baixadas, Centro Fluminense, Norte Fluminense, Noroeste Fluminense, Sul Fluminense, etc. Segundo Golgher (2008), diversos fatores caracterizam uma Região, sendo o econômico o mais importante. Outros fatores também relevantes são os diferentes salários, o acesso ao emprego, o custo diferenciado de moradia e de vida, maiores quantidades de empregos nas empresas, etc. Variáveis não econômicas também são importantes, como, por exemplo, clima favorável, menores índices de criminalidade, mais possibilidades de lazer, menos poluição, menos situações de trânsito, melhores oportunidades de habitação, etc.

Estudar a adaptação acadêmica do estudante universitário, no Rio de Janeiro, possibilita entender se a diversidade e singularidades próprias de cada Região influem nas dificuldades inerentes ao ingresso no ensino superior. Sendo a diferença regional importante, este trabalho buscou identificar as características da 
adaptação de estudantes à universidade, nas mesorregiões do Rio de Janeiro, de forma a oferecer a possibilidade de análise das diferenças e semelhanças no estado.

\section{MÉTODO}

\section{Participantes}

Participaram 500 estudantes do ensino superior, cursando o primeiro ano da graduação, sendo $19 \mathrm{com}$ até 21 anos, 266 com idade entre 21 e 30 anos, 196 com idade entre 31 e 40 anos e 19 com idade acima de 40 anos. Alunos de ambos os gêneros, residentes nas seis principais regiões do Estado do Rio de Janeiro (Metropolitana, Baixadas, Centro Fluminense, Norte Fluminense, Noroeste Fluminenese e Sul Fluminense), sendo 50 alunos de rede pública e 50 alunos de rede privada, totalizando 100 estudantes por cada menor Região, salvo para as regiões Baixadas e Sul Fluminense, onde apenas 50 estudantes, de cada uma das regiões, preencheram os instrumentos, uma vez que, nessas duas regiões, só existem instituições de ensino superior privadas.

Duzentos e quarenta e quatro (244) estudantes afirmaram morar com a família, 153 afirmaram morar sozinhos e 103 dividem residências com os amigos. $50 \%$ dos estudantes moram a até $50 \mathrm{~km}$ da instituição de ensino, 24\% entre 51 e $100 \mathrm{~km}$ da instituição e apenas 3,6\% a uma distância entre 101 e $200 \mathrm{~km}$.

\section{Instrumentos}

Foi adotado, como instrumento de medida, o Questionário de Vivências Acadêmicas (QVA), de Almeida e Ferreira (1997, citado por Almeida e cols., 1999), numa versão adaptada por Villar e Santos (2001, citado por Villar, 2003), para o contexto universitário de acadêmicos brasileiros. Este questionário é um instrumento de autorrelato composto de 170 itens, em formato Likert de cinco alternativas, distribuídos por 17 subescalas, algumas pontuando em mais de uma subescala. Estas subescalas são agrupadas de modo a formar três dimensões: pessoal, realização acadêmica e contextual.

A dimensão pessoal é composta de 6 subescalas: relacionamento com a família (10 itens) $(\alpha=.82)$, autonomia pessoal (12 itens) $(\alpha=.76)$, bem-estar físico (13 itens) $(\alpha=.79)$, bem-estar psicológico (14 itens) $(\alpha=.88)$, autoconfiança (12 itens) $(\alpha=.80) \mathrm{e}$ percepção pessoal de competência (10 itens) $(\alpha=.75)$.

A dimensão de realização é composta de 7 subescalas: bases de conhecimento para o curso (6 itens) $(\alpha=.78)$, métodos de estudo (11 itens) $(\alpha=.76)$, desenvolvimento da carreira (14 itens) $(\alpha=.85)$, relacionamento com professores (14 itens) $(\alpha=.79)$, adaptação ao curso (15 itens) $(\alpha=.85)$, ansiedade na realização de exames (10 itens) $(\alpha=.78)$ e gestão do tempo (8 itens) $(\alpha=.72)$.

A dimensão contextual é composta de 4 subescalas: adaptação à instituição (11 itens) $(\alpha=.74)$, gestão dos recursos econômicos ( 8 itens) $(\alpha=.83)$, relacionamento com colegas (15 itens) $(\alpha=.87)$ e envolvimento em atividades extracurriculares (11 itens) $(\alpha=.69)$.

\section{Procedimentos}

Foi aplicado o instrumento sem restrição de tempo. O questionário foi aplicado aos participantes que já haviam sido submetidos às primeiras provas, conforme recomenda o instrumento em aplicações coletivas, em sala de aula. Os dados sociodemográficos foram coletados em folha de rosto, que precedeu à aplicação dos instrumentos. Todos os participantes assinaram o Termo de Consentimento Livre e Esclarecido. O projeto que deu origem a este trabalho foi aprovado em comitê de ética da Universidade Salgado de Oliveira.

\section{RESULTADOS}

Para realizar a comparação das médias obtidas dos indivíduos classificados, de acordo com as regiões nas subescalas, nas dimensões e no escore total do Questionário de Vivências Acadêmicas, procedeu-se a realização do Teste Correlação Linear de Pearson, conforme mostra a Tabela 1.

Pode-se observar que, em todos os fatores do QVA, foram encontradas diferenças significativas. Para avaliar entre quais regiões as diferenças eram significativas, utilizou-se o teste post hoc de LSD (Least Significant Difference). 
Tabela 1

Médias dos Escores do QVA de Cada Região

\begin{tabular}{|c|c|c|c|c|c|c|c|c|c|}
\hline QVA & & Metropolitana & Baixada & $\begin{array}{l}\text { Centro Flu- } \\
\text { minense }\end{array}$ & $\begin{array}{l}\text { Norte Flumi- } \\
\text { nense }\end{array}$ & $\begin{array}{l}\text { Noroeste } \\
\text { Fluminense }\end{array}$ & $\begin{array}{l}\text { Sul Flumi- } \\
\text { nense }\end{array}$ & $\mathbf{F}$ & $\mathrm{p}$ \\
\hline \multirow[t]{2}{*}{ QVA1 } & Média & 3.42 & 3.04 & 3.14 & 3.11 & 2.85 & 3.25 & 21.261 & 0.000 \\
\hline & D.P. & 0.46 & 0.29 & 0.45 & 0.44 & 0.28 & 0.47 & & \\
\hline \multirow{2}{*}{ QVA2 } & Média & 3.76 & 3.78 & 3.90 & 3.61 & 3.78 & 4.26 & 16.58 & 0.000 \\
\hline & D.P. & 0.55 & 0.29 & 0.48 & 0.39 & 0.36 & 0.39 & & \\
\hline \multirow{2}{*}{ QVA3 } & Média & 3.36 & 3.25 & 3.46 & 3.33 & 3.33 & 3.48 & 6.635 & 0.000 \\
\hline & D.P. & 0.25 & 0.22 & 0.28 & 0.32 & 0.26 & 0.27 & & \\
\hline \multirow[t]{2}{*}{ QVA4 } & Média & 3.36 & 3.12 & 3.14 & 3.15 & 2.98 & 3.47 & 20.481 & 0.000 \\
\hline & D.P. & 0.35 & 0.20 & 0.40 & 0.33 & 0.22 & 0.51 & & \\
\hline \multirow[t]{2}{*}{ QVA5 } & Média & 3.56 & 3.54 & 3.68 & 3.36 & 3.54 & 3.95 & 24.615 & 0.000 \\
\hline & D.P. & 0.38 & 0.24 & 0.32 & 0.33 & 0.24 & 0.40 & & \\
\hline \multirow[t]{2}{*}{ QVA6 } & Média & 3.03 & 3.00 & 2.94 & 3.25 & 2.90 & 2.82 & 12.059 & 0.000 \\
\hline & D.P. & 0.57 & 0.30 & 0.42 & 0.30 & 0.26 & 0.38 & & \\
\hline \multirow[t]{2}{*}{ QVA7 } & Média & 3.00 & 2.97 & 2.77 & 3.09 & 2.93 & 2.74 & 17.304 & 0.000 \\
\hline & D.P. & 0.34 & 0.26 & 0.32 & 0.26 & 0.22 & 0.34 & & \\
\hline \multirow[t]{2}{*}{ QVA8 } & Média & 3.55 & 3.29 & 3.37 & 3.48 & 3.11 & 3.60 & 27.428 & 0.000 \\
\hline & D.P. & 0.35 & 0.26 & 0.35 & 0.36 & 0.25 & 0.28 & & \\
\hline \multirow[t]{2}{*}{ QVA9 } & Média & 3.43 & 3.15 & 3.24 & 3.29 & 3.09 & 3.44 & 23.457 & 0.000 \\
\hline & D.P. & 0.30 & 0.24 & 0.28 & 0.28 & 0.17 & 0.32 & & \\
\hline \multirow[t]{2}{*}{ QVA10 } & Média & 3.57 & 3.21 & 3.44 & 3.44 & 3.15 & 3.65 & 19.84 & 0.000 \\
\hline & D.P. & 0.42 & 0.31 & 0.46 & 0.41 & 0.25 & 0.37 & & \\
\hline \multirow[t]{2}{*}{ QVA11 } & Média & 3.68 & 3.70 & 3.79 & 3.38 & 3.68 & 4.07 & 18.307 & 0.000 \\
\hline & D.P. & 0.66 & 0.26 & 0.46 & 0.32 & 0.31 & 0.48 & & \\
\hline \multirow{2}{*}{ QVA12 } & Média & 3.37 & 2.88 & 2.98 & 3.22 & 2.35 & 3.61 & 57.253 & 0.000 \\
\hline & D.P. & 0.44 & 0.49 & 0.74 & 0.45 & 0.54 & 0.31 & & \\
\hline \multirow[t]{2}{*}{ QVA13 } & Média & 3.27 & 3.50 & 3.53 & 3.33 & 3.46 & 3.64 & 16.471 & 0.000 \\
\hline & D.P. & 0.40 & 0.17 & 0.29 & 0.26 & 0.21 & 0.29 & & \\
\hline \multirow[t]{2}{*}{ QVA14 } & Média & 3.40 & 3.62 & 3.61 & 3.33 & 3.74 & 3.62 & 24.373 & 0.000 \\
\hline & D.P. & 0.32 & 0.28 & 0.34 & 0.32 & 0.25 & 0.27 & & \\
\hline \multirow[t]{2}{*}{ QVA15 } & Média & 3.28 & 3.27 & 3.40 & 3.25 & 3.28 & 3.46 & 4.117 & 0.001 \\
\hline & D.P. & 0.39 & 0.22 & 0.40 & 0.32 & 0.28 & 0.43 & & \\
\hline \multirow[t]{2}{*}{ QVA16 } & Média & 3.47 & 3.12 & 3.17 & 3.31 & 3.21 & 3.13 & 16.009 & 0.000 \\
\hline & D.P. & 0.42 & 0.24 & 0.24 & 0.34 & 0.21 & 0.32 & & \\
\hline \multirow[t]{2}{*}{ QVA17 } & Média & 2.97 & 2.71 & 2.63 & 2.87 & 2.60 & 2.84 & 15.246 & 0.000 \\
\hline & D.P. & 0.55 & 0.23 & 0.31 & 0.35 & 0.24 & 0.35 & & \\
\hline \multirow[t]{2}{*}{ Dimensão } & Média & 3.29 & 3.29 & 3.33 & 3.31 & 3.28 & 3.40 & 6.096 & 0.000 \\
\hline & D.P. & 0.18 & 0.09 & 0.14 & 0.17 & 0.10 & 0.14 & & \\
\hline \multirow[t]{2}{*}{ Dimensão } & Média & 3.38 & 3.15 & 3.20 & 3.21 & 3.03 & 3.43 & 48.999 & 0.000 \\
\hline & D.P. & 0.23 & 0.11 & 0.23 & 0.18 & 0.11 & 0.22 & & \\
\hline \multirow[t]{2}{*}{ Dimensão } & Média & 3.50 & 3.31 & 3.40 & 3.34 & 3.22 & 3.62 & 30.242 & 0.000 \\
\hline & D.P. & 0.31 & 0.12 & 0.22 & 0.22 & 0.13 & 0.19 & & \\
\hline \multirow[t]{2}{*}{ QVATotal } & Média & 3.39 & 3.25 & 3.31 & 3.29 & 3.18 & 3.48 & 39.071 & 0.000 \\
\hline & D.P. & 0.19 & 0.07 & 0.17 & 0.15 & 0.06 & 0.15 & & \\
\hline
\end{tabular}


No QVA 1, bases de conhecimento para o curso, os indivíduos da Região Metropolitana apresentaram escores superiores aos dos indivíduos das demais regiões. Os da Região Baixadas apresentaram escores superiores aos dos indivíduos da Região Noroeste Fluminense $(\mathrm{p}=0.006)$ e inferiores aos dos indivíduos da Região Sul Fluminense ( $\mathrm{p}=0.011)$. Os indivíduos da Região Centro Fluminense apresentaram escores superiores aos dos indivíduos da Região Noroeste Fluminense $(\mathrm{p}=0.000)$. Os da Região Norte Fluminense apresentaram escores superiores aos dos indivíduos da Região Noroeste Fluminense $(\mathrm{p}=0.000)$, mas inferiores aos da Sul Fluminense $(p=0.049)$. Os indivíduos da Região Noroeste Fluminense apresentaram escores inferiores aos dos da Região Sul Fluminense $(\mathrm{p}=0.000)$.

Na subescala 2, relacionamento com a família, os indivíduos da Região Metropolitana apresentaram escores superiores aos dos indivíduos das regiões Centro $(p=0.020)$, Norte $(p=0.014)$ e Sul Fluminense $(p=0.000)$. Os indivíduos da Região Baixadas apresentaram escores superiores aos escores dos indivíduos da Região Norte Fluminense ( $\mathrm{p}=0.028)$, mas inferiores aos dos indivíduos da Sul Fluminense $(\mathrm{p}=$ 0.000). Os indivíduos da Região Centro Fluminense apresentaram escores inferiores aos dos indivíduos da Região Sul Fluminense $(\mathrm{p}=0.000)$ e superiores aos dos indivíduos das regiões Norte $(\mathrm{p}=0.000)$ e Noroeste Fluminense ( $\mathrm{p}=0.037)$. Os indivíduos da Região Norte Fluminense apresentaram escores inferiores aos dos indivíduos das regiões Noroeste Fluminense $(\mathrm{p}=$ $0.007)$ e Sul Fluminense ( $\mathrm{p}=0.000)$. Os indivíduos da Região Noroeste Fluminense apresentaram escores inferiores aos dos indivíduos da Sul Fluminense ( $\mathrm{p}=$ $0.000)$

Quanto a subescala 3, autonomia pessoal, os indivíduos da Região Metropolitana apresentaram escores superiores aos dos indivíduos da Região Baixadas ( $\mathrm{p}=$ 0.021), mas inferiores aos dos indivíduos do Centro ( $\mathrm{p}$ $=0.012)$ e do Sul Fluminense $(\mathrm{p}=0.012)$. Os indivíduos da Região Baixadas apresentaram escores inferiores aos dos indivíduos da Região Centro Fluminense $(\mathrm{p}=0.000)$ e Sul Fluminense $(\mathrm{p}=0.000)$. Os alunos da Região Centro Fluminense apresentaram escores superiores aos dos indivíduos das regiões Norte $(\mathrm{p}=$ $0.000)$ e Noroeste Fluminense ( $\mathrm{p}=0.001)$, enquanto os estudantes da Região Norte Fluminense apresentaram escores inferiores aos dos indivíduos da Região Sul Fluminense $(\mathrm{p}=0.001)$. Os estudantes da Região
Noroeste Fluminense apresentaram escores inferiores aos dos estudantes da Região Sul Fluminense ( $\mathrm{p}=$ $0.002)$

Na subescala 4, métodos de estudo, os estudantes da Região Metropolitana apresentaram escores superiores aos dos escores das demais regiões, com exceção dos escores da Região Sul Fluminense ( $\mathrm{p}=$ 0.062), cuja diferença não foi significativa. Os indivíduos da Região Baixadas apresentaram escores inferiores aos dos da Região Sul Fluminense $(\mathrm{p}=0.000)$, mas superiores aos da Noroeste Fluminense ( $\mathrm{p}=$ 0.014). Os indivíduos da Região Centro Fluminense apresentaram escores superiores aos da Região Noroeste Fluminense ( $p=0.001)$, mas inferiores aos da Região Sul Fluminense $(\mathrm{p}=0.000)$. Os estudantes da Região Norte Fluminense apresentaram escores inferiores aos da Região Sul Fluminense ( $\mathrm{p}=0.001)$ e superiores aos da Região Noroeste Fluminense $(\mathrm{p}=0.000)$. Os indivíduos da Região Noroeste Fluminense apresentaram escores inferiores aos da Região Sul Fluminense ( $p=$ $0.000)$

No QVA 5, desenvolvimento de carreira, os indivíduos da Região Metropolitana apresentaram escores superiores aos das demais regiões, com exceção dos escores da Região Baixadas e da Região Noroeste Fluminense, cuja diferença não foi significativa. Os indivíduos da Região Baixadas apresentaram escores inferiores aos da regiões Centro Fluminense $(\mathrm{p}=$ $0.015)$ e Sul Fluminense ( $\mathrm{p}=0.000)$, mas superiores aos da Região Norte Fluminense $(\mathrm{p}=0.001)$. Os indivíduos da Região Centro Fluminense apresentaram escores superiores aos dos indivíduos das Regiões Norte $(\mathrm{p}=0.000)$ e Noroeste Fluminense $(\mathrm{p}=0.003)$, mas inferiores aos da Sul Fluminense $(p=0.000)$. Os estudantes da Região Norte Fluminense apresentaram escores inferiores aos das regiões Sul Fluminense $(\mathrm{p}=$ $0.001)$ e Noroeste Fluminense $(\mathrm{p}=0.000)$. Os indivíduos das Regiões Noroeste Fluminense apresentaram escores inferiores aos da Região Sul Fluminense ( $\mathrm{p}=$ $0.000)$

Na subescala "bem-estar físico", os indivíduos da Região Metropolitana apresentaram escores superiores aos das regiões Noroeste $(\mathrm{p}=0.015)$ e Sul Fluminense $(\mathrm{p}=0.002)$ e inferiores aos da Região Norte Fluminense $(\mathrm{p}=0.000)$. Os indivíduos da Região Baixadas apresentaram escores inferiores aos da Região Norte Fluminense $(p=0.000)$, mas superiores aos da Sul Fluminense ( $\mathrm{p}=0.023)$. Os alunos da Região Centro Fluminense apresentaram escores inferiores aos da 
Região Norte Fluminense $(\mathrm{p}=0.000)$ e, ainda, os estudantes da Região Norte Fluminense apresentaram escores superiores aos das regiões Sul Fluminense ( $p$ $=0.000)$ e Noroeste Fluminense $(\mathrm{p}=0.000)$.

No QVA 7, bem-estar psicológico, os alunos da Região Metropolitana apresentaram escores superiores aos das regiões Centro $(\mathrm{p}=0.000)$ e Sul Fluminense $(\mathrm{p}=0.000)$ e inferiores aos da Região Norte Fluminense $(\mathrm{p}=0.045)$. Os indivíduos da Região Baixadas apresentaram escores superiores aos das regiões Centro $(\mathrm{p}=0.000)$ e Sul Fluminense $(\mathrm{p}=0.000)$, mas inferiores aos da Norte Fluminense $(p=0.022)$. Os alunos da Região Centro Fluminense apresentaram escores inferiores aos das regiões Norte $(p=0.000)$ e Noroeste Fluminense $(\mathrm{p}=0.000)$. Os indivíduos da Região Norte Fluminense apresentaram escores superiores aos das regiões Sul Fluminense $(p=0.000)$ e Noroeste Fluminense $(\mathrm{p}=0.000)$. Os indivíduos da Região Noroeste Fluminense apresentaram escores superiores aos da Região Sul Fluminense $(p=0.000)$.

$\mathrm{Na}$ subescala 8, relacionamento com professores, os estudantes da Região Metropolitana apresentaram escores superiores aos das demais regiões, com exceção dos escores da Norte e Sul Fluminense, cuja diferença não foi significativa. Os indivíduos da Região Baixadas apresentaram escores inferiores aos das regiões Norte $(p=0.001)$ e Sul Fluminense $(p=0.000)$ e superiores aos da Noroeste Fluminense $(p=0.001)$. Os estudantes da Região Centro Fluminense apresentaram escores inferiores aos das regiões Norte $(\mathrm{p}=$ $0.017)$ e Sul Fluminense ( $p=0.000)$, mas superiores aos da Noroeste Fluminense $(\mathrm{p}=0.000)$. Os indivíduos da Região Norte Fluminense apresentaram escores superiores aos da Região Noroeste Fluminense $(\mathrm{p}$ $=0.000)$ e inferiores aos da Sul Fluminense ( $\mathrm{p}=$ 0.025). Os indivíduos da Região Noroeste Fluminense apresentaram escores inferiores aos da Sul Fluminense $(\mathrm{p}=0.000)$.

No QVA 9, adaptação ao curso, os participantes da Região Metropolitana apresentaram escores superiores aos das demais regiões, com exceção dos escores da Região Sul Fluminense, cuja diferença não foi significativa. Já os da Região Baixadas apresentaram escores inferiores aos das regiões Norte $(\mathrm{p}=0.004)$ e Sul Fluminense $(\mathrm{p}=0.000)$. Os participantes da Região Centro Fluminense apresentaram escores inferiores aos da Região Sul Fluminense $(\mathrm{p}=0.000)$ e superiores aos da Noroeste Fluminense $(\mathrm{p}=0.000)$. Os alunos da
Região Norte Fluminense apresentaram escores superiores aos da Região Noroeste Fluminense $(\mathrm{p}=0.000)$ e inferiores aos da Região Sul Fluminense ( $p=0.001)$, enquanto os da Região Noroeste Fluminense apresentaram escores inferiores aos da Região Sul Fluminense $(p=0.000)$.

Na subescala 10, gestão do tempo, os indivíduos da Região Metropolitana apresentaram escores superiores aos das demais regiões, com exceção dos escores da Região Sul Fluminense, cuja diferença não foi significativa. Os estudantes da Região Baixadas apresentaram escores inferiores aos das regiões Centro ( $\mathrm{p}=$ $0.001)$, Norte $(\mathrm{p}=0.001)$ e Sul Fluminense $(\mathrm{p}=$ 0.000). Os alunos da Região Centro Fluminense apresentaram escores inferiores aos da Sul Fluminense ( $p$ $=0.001)$ e superiores aos da Noroeste Fluminense ( $\mathrm{p}=$ 0.000). Os indivíduos da Região Norte Fluminense apresentaram escores superiores aos da Região Noroeste Fluminense $(\mathrm{p}=0.000)$ e inferiores aos da Sul Fluminense $(\mathrm{p}=0.001)$. Já os indivíduos da Região Noroeste Fluminense apresentaram escores inferiores aos da Sul Fluminense $(\mathrm{p}=0.000)$.

No QVA 11, adaptação à instituição, os indivíduos da Região Metropolitana apresentaram escores superiores aos da Região Norte Fluminense $(\mathrm{p}=0.000)$ e inferiores aos da Sul Fluminense $(\mathrm{p}=0.000)$. Os estudantes da Região Baixadas apresentaram escores superiores aos da Região Norte $(\mathrm{p}=0.001)$ e inferiores aos da Sul Fluminense $(p=0.000)$. Os estudantes da Região Centro Fluminense apresentaram escores inferiores aos da Sul Fluminense $(p=0.001)$ e superiores aos da Norte Fluminense $(\mathrm{p}=0.000)$. Os alunos da Região Norte Fluminense apresentaram escores inferiores aos das regiões Noroeste Fluminense $(\mathrm{p}=$ $0.000)$ e Sul Fluminense ( $\mathrm{p}=0.000)$, enquanto os da Região Noroeste Fluminense apresentaram escores inferiores aos da Sul Fluminense $(\mathrm{p}=0.000)$.

No QVA 12, gestão dos recursos econômicos, os estudantes da Região Metropolitana apresentaram escores superiores aos da maioria da regiões, apresentando escores inferiores, apenas, aos da Sul Fluminense $(\mathrm{p}=0.009)$. Já os da Região Baixadas apresentaram escores inferiores aos das regiões Norte $(p=0.000)$ e Sul Fluminense $(\mathrm{p}=0.000)$, mas superiores aos da Noroeste Fluminense $(\mathrm{p}=0.000)$. Os alunos da Região Centro Fluminense apresentaram escores inferiores aos das regiões Norte $(\mathrm{p}=0.000)$ e Sul Fluminense ( $\mathrm{p}$ $=0.001)$ e superiores aos da Noroeste Fluminense $(\mathrm{p}=$ 
0.000), enquanto os da Região Norte Fluminense apresentaram escores inferiores aos da Região Sul Fluminense $(\mathrm{p}=0.000)$ e superiores aos da Noroeste Fluminense $(\mathrm{p}=0.000)$. Os indivíduos da Região Noroeste Fluminense apresentaram escores inferiores aos da Sul Fluminense $(\mathrm{p}=0.000)$.

No QVA 13, autoconfiança, os indivíduos da Região Metropolitana apresentaram escores superiores aos das demais regiões, com exceção dos escores da Norte Fluminense, cuja diferença não foi significativa. Os alunos da Região Baixadas apresentaram escores inferiores aos da Região Sul Fluminense $(p=0.015)$ e superiores aos da Região Norte Fluminense ( $\mathrm{p}=$ $0.001)$ e Noroeste Fluminense $(\mathrm{p}=0.000)$. Já os indivíduos da Região Centro Fluminense apresentaram escores inferiores aos da Região Sul $(\mathrm{p}=0.024)$ e superiores aos da Norte Fluminense $(\mathrm{p}=0.000)$. Os participantes da Região Norte Fluminense apresentaram escores inferiores aos das regiões Sul Fluminense $(\mathrm{p}=0.000)$ e Noroeste Fluminense $(\mathrm{p}=0.002)$, enquanto os da Região Noroeste Fluminense apresentaram escore inferior ao da Sul Fluminense $(\mathrm{p}=0.000)$.

$\mathrm{Na}$ subescala 14, relacionamento com os colegas, os estudantes da Região Metropolitana apresentaram escores superiores aos das demais regiões, com exceção dos escores da Norte Fluminense, cuja diferença não foi significativa. Os indivíduos da Região Baixadas apresentaram escores inferiores aos da Região Noroeste $(p=0.031)$ e superiores aos da Norte Fluminense ( $p=0.000)$. Os alunos da Região Centro Fluminense apresentaram escores inferiores aos da Região Noroeste $(\mathrm{p}=0.003)$, mas superiores aos da Norte Fluminense $(\mathrm{p}=0.000)$. Os indivíduos da Região Norte Fluminense apresentaram escores inferiores aos das regiões Sul Fluminense $(p=0.000)$ e Noroeste Fluminense $(p=0.000)$, enquanto os das regiões Noroeste Fluminense apresentaram escores superiores aos da Sul Fluminense ( $\mathrm{p}=0.029)$.

Na subescala 15, percepção pessoal de competências cognitivas, os indivíduos da Região Metropolitana apresentaram escores inferiores aos das regiões Centro ( $p=0.015)$ e Sul Fluminense $(p=0.003)$. Os estudantes da Região Baixadas apresentaram escores inferiores aos das regiões Centro $(\mathrm{p}=0.035)$ e Sul Fluminense $(\mathrm{p}=0.008)$ e, ainda, os da Região Centro Fluminense apresentaram escores superiores aos das regiões Norte $(\mathrm{p}=0.003)$ e Noroeste Fluminense $(\mathrm{p}=$ 0.015). Os indivíduos da Região Norte Fluminense apresentaram escores inferiores aos da Região Sul
Fluminense ( $\mathrm{p}=0.001)$. Os alunos da Região Noroeste Fluminense apresentaram escores inferiores aos da Sul Fluminense ( $\mathrm{p}=0.003)$.

Na subescala 16, envolvimento em atividades extracurriculares, os indivíduos da Região Metropolitana apresentaram escores superiores aos das demais regiões. Os estudantes da Região Baixadas apresentaram escores inferiores aos dos indivíduos da Região Norte Fluminense ( $p=0.000)$, enquanto os da Região Centro Fluminense apresentaram escores inferiores aos da Região Norte ( $p=0.001)$. Na Região Norte Fluminense, os estudantes apresentaram escores superiores aos das regiões Sul $(\mathrm{p}=0.000)$ e Noroeste Fluminense ( $\mathrm{p}$ $=0.018$ ).

Na subescala 17, ansiedade na realização de exames, os estudantes da Região Metropolitana apresentaram escores superiores aos das demais regiões, com exceção dos escores da Norte Fluminense, cuja diferença não foi significativa. Os indivíduos da Região Baixadas apresentaram escores inferiores aos da Região Norte Fluminense $(\mathrm{p}=0.013)$, enquanto os da Região Centro Fluminense apresentaram escores inferiores aos das regiões Norte $(\mathrm{p}=0.000)$ e Sul Fluminense $(\mathrm{p}$ $=0.001$ ). Os indivíduos da Região Norte Fluminense apresentaram escores superiores aos da Região Noroeste Fluminense ( $\mathrm{p}=0.000)$, já os da Região Noroeste Fluminense apresentaram escores inferiores aos da Sul Fluminense $(\mathrm{p}=0.000)$.

Na dimensão pessoal, os indivíduos da Região Metropolitana apresentaram escores inferiores aos das regiões Centro $(\mathrm{p}=0.021)$ e Sul Fluminense $(\mathrm{p}=$ 0.000 ), enquanto os da Região Baixadas apresentaram escores inferiores aos da Região Sul Fluminense ( $\mathrm{p}=$ 0.000). Os estudantes da Região Centro Fluminense apresentaram escores inferiores aos da Região Sul ( $p$ $=0.007)$, mas superiores aos da Noroeste Fluminense ( $\mathrm{p}=0.008)$. Os indivíduos da Região Norte Fluminense apresentaram escores inferiores aos da Região Sul Fluminense $(p=0.000)$ e, ainda, os da Região Noroeste Fluminense apresentaram escores inferiores aos da Sul Fluminense $(\mathrm{p}=0.000)$.

$\mathrm{Na}$ dimensão realização, os indivíduos da Região Metropolitana apresentaram escores superiores aos das demais regiões, com exceção dos escores da Região Sul Fluminense, cuja diferença não foi significativa. Os indivíduos da Região Baixadas apresentaram escores inferiores aos da Região Sul Fluminense ( $\mathrm{p}=$ $0.000)$ e Norte Fluminense $(p=0.046)$, mas superiores aos da Noroeste Fluminense $(\mathrm{p}=0.000)$. Os indi- 
víduos da Região Centro Fluminense apresentaram escores inferiores aos da Região Sul $(\mathrm{p}=0.000)$ e superiores aos da Noroeste Fluminense $(\mathrm{p}=0.000)$. Os estudantes da Região Norte Fluminense apresentaram escores inferiores aos da Região Sul Fluminense $(\mathrm{p}=0.000)$ e superiores aos da Noroeste Fluminense $(p=0.000)$. E, ainda, os da Região Noroeste Fluminense apresentaram escores inferiores aos da Sul Fluminense $(\mathrm{p}=0.000)$.

Na dimensão contextual, os indivíduos da Região Metropolitana apresentaram escores superiores aos da maioria das regiões, mas inferiores aos da Sul Fluminense $(\mathrm{p}=0.001)$. Os alunos da Região Baixadas apresentaram escores inferiores aos das regiões Sul Fluminense $(\mathrm{p}=0.000)$ e Centro Fluminense $(\mathrm{p}=$ 0.014), mas superiores aos da Noroeste Fluminense ( $p$ $=0.029$ ). Os participantes da Região Centro Fluminense apresentaram escores inferiores aos da Região Sul $(\mathrm{p}=0.000)$ e superiores aos da Noroeste $(\mathrm{p}=$ $0.000)$ e Norte Fluminense ( $p=0.046)$. Os estudantes da Região Norte Fluminense apresentaram escores inferiores aos da Região Sul Fluminense $(p=0.000)$ e superiores aos da Noroeste Fluminense $(p=0.000)$, enquanto os indivíduos das Regiões Noroeste Fluminense apresentaram escores inferiores aos da Região Sul Fluminense $(\mathrm{p}=0.000)$.

No escore total, os participantes da Região Metropolitana apresentaram escores superiores aos dos indivíduos da maioria das regiões, mas inferiores aos da Região Sul Fluminense $(\mathrm{p}=0.000)$. Os estudantes da Região Baixadas apresentaram escores inferiores aos das regiões Sul Fluminense $(\mathrm{p}=0.000)$ e Centro Fluminense $(p=0.014)$, mas superiores aos da Noroeste Fluminense $(p=0.004)$. Os indivíduos da Região Centro Fluminense apresentaram escores inferiores aos da Região Sul $(\mathrm{p}=0.000)$ e superiores aos da Noroeste $(\mathrm{p}=0.000)$, enquanto os da Região Norte Fluminense apresentaram escores inferiores aos da Região Sul Fluminense $(\mathrm{p}=0.000)$, mas superiores aos da Região Noroeste Fluminense $(\mathrm{p}=0.000)$. Os estudantes das Região Noroeste Fluminense apresentaram escores inferiores aos da Região Sul Fluminense $(p=0.000)$.

\section{DISCUSSÃO}

Com relação aos resultados apresentados, observase que a Região Metropolitana se destaca no item referente a base de conhecimentos para o curso, evidenciando que os estudantes que ingressam na vida acadêmica das instituições desta Região estão bem preparados para enfrentar estudos superiores. Segundo Almeida e Soares (2004), uma questão essencial para a aprendizagem e para o sucesso dos alunos em formação acadêmica é o conhecimento que trazem do ensino médio. Algumas investigações tem demonstrado que o conhecimento adquirido no ensino médio é um bom preditor, isoladamente, do desempenho acadêmico dos estudantes universitários (Marques \& Miranda, 1993; Soares e cols., 2006). A seleção dos estudantes universitários, nesta região, faz com que somente aqueles mais preparados, de uma grande demanda de candidatos, possam ter acesso ao ensino universitário, garantindo, assim, que possam dar continuidade, de modo eficiente, a seus estudos. Os alunos desta região também mostram estar adaptados no que diz respeito ao relacionamento com os familiares, envolvimento com o desenvolvimento da carreira, relação com os professores, adaptação ao curso e gestão do tempo. São autoconfiantes e envolvidos com atividades extracurriculares, porém demonstram ansiedade na realização dos exames.

Segundo Pachane (2004), a grande demanda do mercado pela qualificação tem levado os cursos superiores a se direcionar para a busca de uma formação técnica e da aquisição de conhecimentos e competências, na intenção de atender às exigências econômicas e finaceiras do mercado de trabalho. Entretanto, o que se tem observado é que o grande diferencial do ensino superior tem sido o desenvolvimento pessoal dos alunos, propiciando que, em um processo de amadurecimento, o aluno possa vir a ter uma visão de mundo mais ampliada, mais diversificada. Ainda segundo Pachane (2004), para que este desejo de desenvolvimento pessoal se realize, é preciso que o aluno esteja apto a vencer uma série de dificuldades adaptativas, passando a adequar suas expectativas quanto à universidade, seus vínculos, seus conceitos, valores e laços afetivos.

É sob a pressão do mercado que os estudantes da Região Metropolitana alimentam este desejo de crescimento pessoal, para alcançar o diferencial da empregabilidade. Embora indiquem ficar ansiosos na realização de exames, pois sabem que deles dependem para concluir o curso, sabem, também, o quanto é importante envolver-se com o desenvolvimento da carreira, relacionando-se bem com seus profesores e gerindo bem seu tempo disponível. A autoconfiança está associada a uma boa base de conhecimentos ante- 
riores para o curso e, também, ao envolvimento com atividades extracurriculares, que, segundo Fior e Mercuri (2004), só vem a enriquecer a diversidade da experiência acadêmica e a consolidar o sentido de eficiência pessoal.

Os alunos da Região Sul Fluminense apresentam maiores escores quanto a relação com os professores, autonomia pessoal, métodos de estudo, adaptação à instituição e ao curso, gestão de recursos e percepção de competência pessoal. Trata-se de uma região próspera, com economia em desenvolvimento, principalmente na área tecnológica (metalmecânica, automotiva, metalúrgica, siderúrgica), que propõe um nível de empregabilidade alto, fazendo com que os estudantes universitários possam realizar seus estudos com maior autonomia pessoal financeira, o que se relaciona, também, com a gestão de seus próprios recursos. Esta autonomia permite a eles uma melhor adaptação à instituição e uma alta percepção de autoeficácia, ou seja, uma percepção de competência pessoal. Autonomia financeira, percepção de competência, bons métodos de estudo e bom relacionamento com os professores faz com que os estudantes mantenham um bom nível de relacionamento, adaptando-se com tranquilidade ao curso.

Em um estudo de Kumar, Silva e Paixão (2007), realizado com 474 sujeitos que frequentam instituições de ensino superior e utilizando O Questionário de Exploração de Projectos de Vida nos Estudantes do Ensino Superior, obteve-se como resultado que os estudantes atribuem, em média, maior importância aos projetos educativos, de formação e/ou profissional e de desenvolvimento pessoal, enfatizando a relevância e consideração aos projetos ligados com a sua formação acadêmica, a preparação da sua inserção no mercado de trabalho e de suas perspectivas profissionais, e refletem, ainda, o significado identificado aos projetos relacionados com a sua estabilidade afetiva, assim como, aos que incluem o desenvolvimento de competências pessoais de autonomia, identidade, autoconfiança e perseverança (p. 54).

Os estudantes da Região Sul Fluminense se encontram, plenamente, vivenciando os aspectos pessoalafetivos (autonomia pessoal, percepção de competências cognitivas), de satisfação, compromisso e realização (relacionamento com professores, adaptação ao curso e gestão do tempo) e sociocontextuais, relacionados à "adaptação à instituição" e "à gestão de recur- sos". Nesta região, todos os estudantes pesquisados frequentam instituições privadas de ensino e, assim como em Soares e cols. (2009), levando em conta que a população pesquisada nas instituições privadas é prioritariamente de estudantes que subsidiam seus estudos; este fato pode ter proporcionado uma percepção significativamente maior da autonomia pessoal, administração dos recursos e decorrente adaptação à instituição e ao curso.

Os estudantes da Região Norte Fluminense destacam-se quanto ao bem-estar físico, bem-estar psicológico, relacionamento com os professores e com os colegas, assim como em autoconfiança. Nesta região, encontram-se, em desenvolvimento, universidades que ainda estão há pouco tempo instaladas na região. São estudantes que convivem muito proximamente, entre eles e com seus professores, dado que ainda, comparativamente a outras regiões, são oferecidas poucas opções de cursos universitários e que o contingente estudantil ainda é pequeno. Agrega-se a este fato que a oferta de empregos para profissionais qualificados é significativa, o que pode gerar um certo conforto psíquico e físico para os estudantes em formação.

A Região Noroeste Fluminense mostra que seus estudantes se relacionam melhor entre eles do que os de outras regiões. É uma região muito pobre, que encontra, provavelmente, na solidariedade entre os próprios estudantes o diferencial para superar as dificuldades. Em estudo de Teixeira, Dias, Wottrich e Oliveira (2008), com 14 estudantes de diferentes cursos, a análise das entrevistas aponta que, de um modo geral, a adaptação à universidade entre ingressantes depende de inúmeras questões, sendo que algumas delas, direcionadas para o contexto não acadêmico, como, por exemplo, o fato do estudante morar com ou sem família e a própria rede, suporte social de amizades, que o estudante pode contar extracontexto universitário.

Encontram-se maiores escores para a dimensão pessoal e contextual para os alunos da Região Sul Fluminense. Para a dimensão de realização, os maiores escores estão igualmente na Região Sul Fluminense e na Metropolitana. Vê-se, aqui, conforme já explicitou-se anteriormente, que os estudantes do sul fluminense têm um ambiente propício para a adaptação à universidade, tanto no que diz respeito a aspectos que se relacionam a si próprios, como à autonomia pessoal e à percepção de competências, quanto ao contexto do 
ambiente que os cerca, que se refere, principalmente, à gestão de recursos econômicos. Na dimensão de realização, os estudantes da Região Metropolitana encontram-se, também, realizados, uma vez que se envolvem no desenvolvimento de suas carreiras, para uma futura melhor qualidade de vida.

Com relação a esse aspecto, vale ressaltar que a Região Metropolitana do Rio de Janeiro, tal como considerada pelo Instituto Brasileiro de Geografia e Estatística (IBGE), ostenta um PIB de R \$ 172.563,00 (cento e setenta e dois bilhões e quinhentos e sesssenta e três mil reais), constituindo o segundo maior polo de riqueza nacional; concentra $70 \%$ da força econômica do estado e $8,04 \%$ de todos os bens e serviços produzidos no país. Há muitos anos, concentra o segundo maior polo industrial do Brasil, contando com vários segmentos organizacionais. Dadas estas características da região, cada vez mais a metrópole contribui para o polo nacional de serviços e negócios, apresentando uma demanda maior de profissionais. Ou seja, a Região Metropolitana do Rio de Janeiro precisa ter mais universidades para abarcar estudantes que estão em busca de uma formação acadêmica.

\section{CONSIDERAÇÕES FINAIS}

Segundo Seco, Pereira, Dias, Casimiro e Custódio (2005), um número importante de investigações tem enfatizado a ideia que uma adaptação de qualidade requer níveis de ajustes e emparelhamento entre as características pessoais dos estudantes, tais como expectativas, valores, etc., e a abordagem acadêmica de funcionamento, estrutura e financiamento, oferecida pela universidade. Assim, as instituições de nível superior devem inserir e oferecer nas suas estratégias de intervenção, clareza e consistência de objetivos e metas de desenvolvimento e de desempenho desejáveis, realizando atendimento de apoio aos seus alunos, que permitam, cobrindo um amplo campo de atuação, seja no que tange a pluralidade de estudantes seja relativo aos problemas acadêmicos ou aos socialmente mais generalizantes.

Tendo em vista que cada região do Rio de Janeiro encontra, em sua constituição, diversidades econômicas e culturais que propiciam fontes de recursos adaptativos diferentes, esta pesquisa buscou evidenciar características de vivências acadêmicas de estudantes universitários frequentadores de diferentes regiões do Estado do Rio de Janeiro. A pesquisa contribuiu não só para comparar as vivências acadêmicas nas mesorregiões do Rio de Janeiro, mas também para ressaltar a importância da adaptação acadêmica ao contexto universitário, já que a mesma avalia as relações que são estabelecidas pelo aluno com a instituição e com os colegas, professores que estão envolvidos neste contexto, bem como seu bem-estar físico e psicológico. Dentro deste contexto, ainda seria interessante investigar, em cada região, as diferenças entre instituições de ensino públicas e privadas, assim como a diferença de gênero e idade, face à adaptação à universidade.

\section{REFERÊNCIAS}

Almeida, L. S. (1998). Adaptação, rendimento e desenvolvimento dos estudantes do ensino superior: Estudo junto dos alunos do $1^{\circ}$ ano da Universidade do Minho. Braga: CEEP.

Almeida, L. S., \& Soares, A. P. (2004). Os estudantes universitários: Sucesso escolar e desenvolvimento psicossocial. Em E. Mercuri \& S. A. J. Polydoro (Orgs.), Estudante universitário: Características e experiências de formação (pp. 15-40). Taubaté: Cabral.

Almeida, L. S., Soares, A. P. C., \& Ferreira, J. A. G. (1999). Adaptação e rendimento acadêmico no ensino superior: Fundamentação e validação de uma escala de vivências acadêmicas. Psicologia: Teoria, Investigação e Prática, 1, 157-170.

Azevedo, A., \& Faria, L. (2001). Impacto das condições pessoais e contextuais na transição do ensino secundário para o ensino superior. Revista da UFP, 6, 257-269.

Azevedo, A. S., \& Faria, L. (2006). Motivação, sucesso e transição para o ensino superior. Psicologia, 20, 69-93.

Balassiano, M., Seabra, A. A., \& Lemos, A. H. (2005). Escolaridade, salários e empregabilidade: Tem razão a teoria do capital humano? Revista de Administração Contemporânea, 9, 31-52.

Cunha, S. M., \& Carrilho, D. M. (2005). O processo de adaptação ao ensino superior e o rendimento acadêmico. Psicologia Escolar e Educacional, 9, 215-224.

Ferreira, J. A., Almeida, L. S., \& Soares, A. P. (2001). Adaptação acadêmica em estudantes do $1^{\circ}$ ano: Diferenças de gênero, situação de estudantes e cursos. Psicologia, 6, 1-10.

Fior, C. A., \& Mercuri, E. (2004). Formação universitária: O impacto das atividades não obrigatórias. Em E. Mercuri \& S. A. J. Polydoro (Orgs.), Estudante universitário: Características e experiências de formação (pp. 129-154). Taubaté: Cabral.

Golguer, A. B. (2008). As cidades e a classe criativa no Brasil: Diferenças espaciais na distribuição de indivíduos qualificados nos municípios brasileiros. Revista Brasileira Estudos de População, 25, 109-129.

Granado, J. I. F., Santos, A. A. A., Almeida, L. S., Soares, A. P., \& Guisande, M. A. (2005). Integração acadêmica de estudantes universitários: Contributos para a adaptação e validação do QVAr no Brasil. Psicologia e Educação, 12, 31-43.

Instituto Nacional de Estudos e Pesquisas Educacionais (2006). Portal permitirá acesso às informações do ensino superior. 
Retirado de http://portal.mec.gov.br/index.php?option=com content $\&$ view $=$ article \&id=7421:\&catid=212\&Itemid $=86$

Kumar, M. E., Silva, J. T., \& Paixão, M. P. (2007). Os projectos de vida nos estudantes do ensino superior: Relação com o optimismo e a auto-eficácia de carreira. Revista Psychologica, 44, $45-62$.

Marques, J. F., \& Miranda, M. J. (1993). Sobre o acesso ao ensino superior em Portugal: Estudo de indicadores suma amostra de estudantes de Lisboa. Revista Portuguesa de Psicologia, 29, 111-140.

Pachane, G. G. (2004). A experiência universitária e sua contribuição ao desenvolvimento pessoal do aluno. Em E. Mercuri \& S. A. J. Polydoro. (Orgs.), Estudante universitário: Características e experiências de formação (pp. 155-186). Taubaté: Cabral.

Parker, J. D. A., Summerfeldt, L. J., Hogan, M. J., \& Majeski, S. A. (2004). Emotional intelligence and academic success examining the transition from high school to university. Personality and Individual Differences, 36, 163-172.

Pascarella, E. T., \& Terenzini, P. (1991). Twenty years of research on college students: Lessons for future research: Vol. 1. San Francisco: Jossey-Bass.

Pascarella, E. T., \& Terenzini, P. T. (2005). How college affects students: A third decade of research: Vol. 2. San Francisco: Jossey-Bass.

Pires, H. S., Almeida, L., \& Ferreira, J. A. (2000). Questionário de Vivências Acadêmicas (QVA) aos estudantes universitários dos PALOP. Em A. P. Soares, A. Osório, J. V. Capela, L. S. Almeida, R. M. Vasconcelos \& S. M. Caíres (Orgs.), Transição para o ensino superior (pp. 119-127). Braga: Universidade de Minho.

Polydoro, S. A. J. (2000). O trancamento de matrícula na trajetória acadêmica do universitário: Condições de saída e de retorno à universidade. Tese de doutorado não-publicada, Universidade Estadual de Campinas.
Polydoro, S. A. J., Primi, R., Serpa, M. N. F., Zaroni, M. M. H., \& Pombal, K. C. P. (2001). Desenvolvimento de uma escala de integração ao ensino superior. Psico-USF, 6, 11-17.

Seco, M. S. B., Pereira, I., Dias, I., Casimiro, M., \& Custódio, S. (2005). Para uma abordagem psicológica da transição do ensino secundário para o ensino superior: Pontes e alçapões. Psicologia e Educação, 4, 7-21.

Soares, A. B., Poubel, L. N., \& Mello, T. V. S. (2009). Habilidades sociais e adaptação acadêmica: Um estudo comparativo em instituições de ensino público e privado. Aletheia, 29, 27-42.

Soares, A. P., Almeida, L. S., Diniz, A., \& Guisande, M. A. (2006). Modelo Multidimensional de Ajustamento de jovens ao contexto Universitário (MMAU): Validação com alunos de ciências e tecnologias versus alunos de ciências sociais e humanas. Análise Psicológica, 1, 15-28.

Soares, A. P., Guisande, A. M., Almeida, L. S., \& Páramo, F. M. (2008). Academic achievement in first-year Portuguese college students: The role of academic preparation and learning strategies. International Journal of Psychology, 44, 204-212.

Teixeira, M. C. P., Dias, A. C. G., Wottrich, S. H., \& Oliveira, A. M. (2008). Adaptação à universidade em jovens calouros. Psicologia Escolar e Educacional, 12, 185-202.

Vendramini, C. M. M., Santos, A. A. A., Polydoro, S. A. J., Sbardelini, E. T. B., Serpa, M. N. F., \& Natário, E. G. (2004). Construção e validação de uma escala sobre avaliação da vida acadêmica (EAVA). Estudos de Psicologia (Natal), 9, 259268.

Villar, J. D. (2003). Adaptação de questionário de vivência universitária com estudantes de arquitetura e engenharia. Dissertação de mestrado não-publicada, Universidade São Francisco, Itatiba. 